\title{
МЕДИАЦИЯ КАК МЕЖДИСЦИПЛИНАРНОЕ СОТРУДНИЧЕСТВО
}

\author{
Е. Н. Иванова \\ Санкт-Петербургский государственный университет \\ Поступила в редакцию 10 марта 2021 г.
}

\begin{abstract}
Аннотация: статья посвящена актуальной проблеме взаимовыгодного взаимодействия медиаиии и других направлений науки и практики. Обоснована многогранность медиации как метода работь с конбблктали и проблемали и ее отражение в профбессиональньх требованиях к медиатору. Рассмотрень преилущества, которые медиаиия и медиаторы получают от междисииплинарного сотрудничества на нескольких уровнях (на примере юриспрудениии, психологии, психотерапии и теории переговоров). Показаны перспективы медиации как практики и теории в сотрудничестве с другили дисииплинали. Подчеркивается и раскрывается не только обогащение медиации за счет влияния других направлений научного знания и практики, но и выгодность взаимодействия с медиацией для салих этих направлений. Отлечается, что плодотворное междисииплинарное сотрудничество уже существует, однако его потенииал не раскрыт, и эти ресурсы могут быть приумножены на базе медиаиии.
\end{abstract}

Ключевые слова: медиация, междисииплинарное сотрудничество, взаимные преилущества, многогранность.

\begin{abstract}
: the article is concerned with the actual problem of mutually profitable cooperation of mediation and other directions of science and practice. Mediation versatility as a method of work with conflicts and problems and their reflection in professional demands to mediator is substantiated. The preferences mediation and mediators get from multidisciplinary collaboration at several levels are shown on the example of jurisprudence, psychology, psychotherapy and negotiation theory. Mediation perspectives as practice and theory in collaboration with other disciplines are demonstrated. Is accentuated and shown that this is not only mediation's enrichment due to influence of other directions of scientific knowledge and practice taking place, but profitability of interaction with mediation for them exists also. Its noticed that fruitful interdisciplinary collaboration exists already, but its potential isn't revealed yet and these resources could be multiplied on the basis of mediation.
\end{abstract}

Key words: mediation, interdisciplinary collaboration, mutual preferences, versatility.

Медиация в ее современной форме изначально возникла и развивалась как междисциплинарная область, как один из видов альтернативного разрешения споров (AРC). В юридическом плане АРС понимается как способ, альтернативный государственной судебной системе. В более широком смысле - как конструктивное дополнение ко всем формальным, жестким, в том числе административным формам преодоления конфрликтов и проблем. В наиболее широком подходе АРС означает все возможные

(C) Иванова Е. Н., 2021 


\section{Вестник ВГУ. Серия: Право}

виды работы с конфликтными ситуациями и включает, помимо перечисленных, конфликтологическое, психологическое, психотерапевтическое консультирование, фрасилитацию, коучинг, обучение для повышения конфликтологической компетентности и другие варианты помощи спорящим сторонам.

Деятельность медиатора практически универсальна и прекрасно вписывается в любой из этих подходов. Более того, после довольно длительного периода, когда медиация рассматривалась как сугубо прикладная область, в последние десятилетия сформировался явный запрос на формирование теории медиации и происходит ее активное развитие ${ }^{1}$. Этот процесс явился логическим следствием расширения медиационной практики, ее распространения на разнообразные сфреры жизнедеятельности общества. Новые задачи сорормировали дополнительные профрессиональные требования к медиаторам, повлекли за собой совершенствование технологии медиации и обогащение ее методического арсенала ${ }^{2}$. Как отметил Тьери Гарби, сегодня нельзя обучать медиации так же, как 20 лет назад ${ }^{3}$.

Современный медиатор, даже если он специализируется на какой-то отдельной сфере деятельности, должен обладать широчайшим спектром знаний, умений и навыков. Традиционно выделялись коммуникативные, переговорные и собственно медиативные навыки. Высокие требования предъявляются не только непосредственно к способности медиатора помочь сторонам справиться с их осложнениями в данный момент, но и к соблюдению этических норм, а также базовых принципов медиатора, что порой вступает в противоречие со статистикой, отражающей количество заключенных соглашений. Расширение и интенсификация практики показали, что ключевыми являются также навыки медиатора, обеспечивающие его саморегуляцию как важнейший залог сохранения нейтральности и профрилактики профессионального выгорания.

Медиация исходит из того, что стороны - сами эксперты по своей проблеме, и медиатор не дает им советов и не принимает за них решение. В конфликте у сторон искажаются и становятся необъективными восприятие ситуации, оппонентов, себя и своей роли, мышление и принятие решений, эмоции и чувства, целеполагание и поведение. Стороны видят ситуацию в черно-белых тонах, демонизируют оппонента, не слышат и не понимают друг друга, неверно определяют баланс сил, недооценивая противника, который может нанести чувствительный урон, питают иллюзии по поводу перспектив спора, застопориваются на позициях, часто не отвечающих их интересам.

${ }^{1}$ Cm.: Advancing Workplace Mediation Through Integration of Theory and Practice. Springer International Publishing, Switzerland, 2016.

${ }^{2}$ См.: Иванова E. H. Медиация : возможности vs. Ограничения // Конфликт как проблема. Очерки современной теоретической и прикладной конфрликтологии. СПб., 2015. С. 412-433.

${ }^{3}$ Cм.: Garby T. Agreed! Negotiation/mediation in the 21st century. ICC Publications, 2016. 
Медиатор помогает оценить и выровнять соотношение сил сторон, понять и удовлетворить их реальные долгосрочные интересы.

Поскольку задачей медиатора является не разобраться в ситуации и решить проблему самому, а помочь сторонам справиться с эмоџиями, увидеть конкретные объективные обстоятельства, осознать реальные последствия и понять свои истинные интересы, выработать взаимоприемлемые решения самостоятельно, то его работа становится еще более сложной. Медиатору сложно справиться не только с иррациональностью сторон, но и с желанием подсказать им наилучшее с его точки зрения решение. Особенно сложно справиться с директивностью и давлением на клиентов тем медиаторам, которые в соответствии с их базовым профессиональным образованием играют роль экспертов в юридической, экономической, психотерапевтической, образовательной и других сферах ${ }^{4}$.

Поэтому не удивительно, что список дисциплин, которые вносят в практику и теорию медиации необходимый и существенный вклад, чрезвычайно широк. Среди них: философия, юриспруденция, филология, социология, психология, физиология, экономика, история, конфликтология, математика, политология, этика, логика, педагогика, дизайн, искусствоведение, биология, менеджмент, медицина и многие другие области знания.

Важно отметить, что процесс поддержки и обогащения в отношениях между медиацией и ее "соучастниками» является не односторонним, а взаимным. Он происходит на нескольких уровнях - от общегосударственного до межгруппового и индивидуального.

Например, не вызывает сомнений огромный вклад юридических дисциплин как в подготовку и защиту медиаторов, создание легальной базы для проведения медиаций и реализации ее результатов, так и в развитие, институционализацию медиации, содействие упрочению ее позиций и формированию позитивного имиджа в обществе. В случае формирования отношений сотрудничества между представителями медиации и судебной системы адвокаты, судьи и другие сотрудники правоохранительной системы становятся поставщиками медиаторов. Адвокаты консультируют своих клиентов в ходе медиации или между сессиями, помогают проверить соглашение на соответствие закону, отформатировать его для заверения нотариально или в качестве мирового соглашения и во многом другом.

Вместе с тем медиация обогащает юридическую теорию и практику, способствует ее гуманизации, помогает справиться с бесперспективными с юридической точки зрения делами, снижает число апелляций и жалоб граждан на судебные органы, в ближайшем будущем (а в ряде стран уже сегодня) поможет справиться с перегрузкой судебной системы. Медиация дает юристам многие полезные навыки для более әффективной работы с клиентами, помогает разрешать возникающие у самих юристов

${ }^{4}$ См.: Иванова E. Н. Динамика директивности при обучении медиации // Вестник СПбГУ. 2014. Вып. 6. С. 80-87. 
конфликты, снижает уровень профрессионального выгорания. Многие американские адвокаты, например, говорят, что занимаются медиацией «для души».

Психологические дисциплины раскрывают сущность когнитивных и эмоциональных процессов, истоки иррациональности принятия решений ${ }^{5}$ обеспечивают разнообразные техники работы с информацией, преодоления стереотипов, установления контакта и доверия, создания благоприятной атмосферы для ведения переговоров, оттачивания главного инструмента медиатора - его личности, отработки собственных проблем. Психологические теории объясняют особенности индивидуального, внутри- и межгруппового поведения, раскрывая механизмы социального влияния, и вооружают медиатора инструментами для использования этих знаний на практике. Многие психологи также рекомендуют своим клиентам обратиться к медиатору.

В свою очередь медиация, постоянно находясь на переднем крае столкновений между людьми, выявляет многие закономерности человеческого взаимодействия, которые особенно ярко проявляются в конфликте. Медиация оснащает психологов средствами налаживания взаимопонимания и достижения договоренностей между клиентами, в чем представители психологии часто отмечают потребность. Овладение медиативной технологией повышает квалификацию, успешность и востребованность психологов-практиков, помогает разрешать внутриорганизационные и личные конфрликты в этой сфрере.

Психотерапия и даже психиатрия вносят свой значительный вклад в развитие и применение медиации. Базовые техники передразирования и другие виды работы с информацией и налаживанием контакта происходят из клиент-центрированной терапии Карла Роджерса. Многие - направления медиации ведут свое происхождение из различных школ психотерапии. Например, нарративная медиация 6 вытекает из нарративной психотерапевтической практики, системная семейная - из интегративной семейной терапии ${ }^{7}$, трансформативная ${ }^{8}-$ из гуманистической и т. д. Психотерапевтические школы, кроме того, помогают медиаторам разобраться в себе, отработать внутриличностные проблемы. Например, использование идей Боуэна и системных методов помогает медиатору

не только справиться с проявлениями психического заражения, безответственности клиентов, но и повысить собственную дифференцированность, т. е. степень разграничения эмоционального и интеллектуального функционирования, а также избежать триангуляции - вовлечения в от-

${ }^{5}$ См.: Канелан Д. Думай медленно... решай быстро». М., 2014.

${ }^{6}$ Cм.: Winslade J., Monk G. Practicing Narrative Mediation. Jossey-Bass, 2008.

${ }^{7}$ Cм.: Regina W. F. Applying Family Systems Theory to Mediation. Lanham, Maryland, 2011.

${ }^{8}$ Cm.: Bush R., Folger J. The Promise of Mediation. The Transformative Approach to Conflict. Jossey-Bass, 2005. 
ношения между сторонами в качестве третьего члена и потери нейтральности ${ }^{9}$.

Транзактный анализ ${ }^{10}$, базовые идеи которого родственны медиации, помогают справиться со многими сложными случаями за счет подстройки к состояниям «Я» клиентов, учета жизненных сценариев, трансформации драматического треугольника Карпмана в эмпатический ${ }^{11}$, использования концепции типов личностных адаптаций и использования «открытых дверей» вместо «дверей-ловушек» Уэра ${ }^{12}$.

Тем не менее, используя технические приемы психотерапии, медиация не только сохраняет свою специфичность, но и обогащает психотерапевтическую область идеями, фрактами, инновационными методическими разработками ${ }^{13}$.

Теория интегративных, ориентированных на сотрудничество переговоров, лежит в основе медиации ${ }^{14}$. Как уже отмечалось, переговорные навыки, способность различать позиции и интересы, составлять список вопросов для обсуждения, определять процедурные соглашения, фрормулировать предложения, не вызывающие сопротивления, фрормировать работающее долгосрочное соглашение и многие другие базовые возможности являются постоянно пополняемым ресурсом медиации. Исследования в сфере переговоров открывают новые возможности и расширяют круг медиабельных случаев за счет повышения переговорного мастерства и уверенности медиаторов. Например, они показывают, что люди, которые могут оценивать интересы оппонента более точно, обычно достигают лучших результатов, чем те, которые концентрируются только на своих целях. Профрессиональные переговорщики тратят в 4 раза больше времени на рассмотрение общих интересов, что составляет 40 \% их времени на подготовку по сравнению с 10 \% у непрофессионалов.

Медиация как специфический вид переговоров способствует их успешному течению во многих случаях, когда стороны самостоятельно договориться не могут. Участие в медиации дает переговорщикам модель успешного поведения в сложных переговорных ситуациях. В ходе медиативной практики вырабатываются новые техники и стратегии взаимодействия, которые обогащают переговорную теорию и расширяют инструментарий профрессиональных переговорщиков.

В рамках статьи не представляется возможным рассмотреть все аспекты взаимодействия медиации с другими сферами знания и практики. Главное, что представляется необходимым отметить - междисципли-

${ }^{9}$ См.: Иванова E. Н. Проблема диффреренцированности в медиации // Конфрликтология. 2017. № 3. С. 205-219.

${ }^{10}$ См.: Стюарт И., Джсойнс В. Современный транзактный анализ. СПб., 2017.

${ }^{11}$ См.: Карплан С. Жизнь, свободная от игр. СПб., 2016.

${ }^{12}$ См.: Джойнс В., Уэр И. Личностные адаптации. СПб., 2019.

${ }^{13}$ См.: Иванова E. H. Метод трансформации драматического треугольника Карпмана в процессе медиации. Красноярск, 2020.

14 См.: Ведение переговоров с установкой на сотрудничество / под ред. Е. Н. Ивановой. Рига ; СПб., 1995. 
нарное сотрудничество существует, приносит плоды, однако его потенциал далеко не исчерпан. Взаимообогащение, совмещение профрессий, повышение квалификации, личностный рост, создание междисциплинарного профессионального сообщества, профилактика монотонности и эмоционального выгорания - только малая часть выгод от такого сотрудничества. Раскрытие и использование ресурсов междисциплинарного сотрудничества на ниве медиации принесет пользу всем участникам этого взаимодействия и самому обществу в полном соответствии с базовой идеей переговоров с участием нейтрального посредника.

Санкт-Петербургский государственный университет

Иванова Е. Н., кандидат психологических наук, доцент кафбедры конфбликтологии, руководитель Службь конфбликтологического консультирования и медиации (клиники медиации)

E-mail:elenaiv1@mail.ru
St. Petersburg State University

Ivanova E. N., Candidate of Psychological Sciences, Associate Professor of the Conflictology Department, Head of the Conflict Counseling and Mediation Service (Mediation Clinic)

E-mail: elenaiv1@mail.ru 